\title{
Homenaje a Menéndez Pidal
}

A significación de don Ramón Menéndez Pidal en los [0. estudios de historia literaria europeos es considerable. Numerosos libros que agotan algunos de los lemas de su especialidad representan la contribución de este sabio al progreso de esa disciplina. Además, veinticinco años de prolesorado. fecundos por su ejemplo y por sus más directos [rutos, los discipulos y continuadores de la labor del maestro, completan una actividad formidable. No es extraño, por esto, que el homenaje tributado a Menéndez Pidal haya sido un acontecimiento. no sólo para España. El 7 de Marzo del año en curso se efectuó en Madrid esta solemnidad de la cual queremos dar una breve reseña en las lineas que siguen.

El día señalado se verificó, en el Centro de Estudios Históricos, la fiesla conmemorativa a que aludimos. Consistió en la entregá al sabio de un ejemplar de la obra que han formado. con trabajos compuestos ad-hoc, muchos investigadores, eruditos y criticos literarios de diversos paises. Dicha obra consta de tres grúesos volúmenes impresos por la casa editora Hernando. que ha auspiciado entusiastamente el homenaje. En estos volúmenes colaboran escritores españoles en gran número, desde el Duque de Alba hasta Américo Castro. Los nombres de Manuel Gómez Moreno. Miguel de Unamuno. T. Navarro Tomás. Julio Casares, M. Asin Palacios. Federico de Onís. Pedro Salinas, Rodriguez Marín, etc.. representan, además, a la madre patria. Los extranjeros son más, y entre ellos puede citarse, de pronto, a los siguientes: O. J. Tallgren, J. Leite de Vasconcellos, Leo Spitzar, C. Carroll Marden, W. Meyer-Lübke, A. 
Meillet, Wechssler, E. Bourciez, G. Millardet, J. D. M. Ford. Sin olvidar. por cierto, a Fidelino de Figueiredo. Vincenzo Crescini, Walter Starkie. A. Jeanroy. A. Morel-Falio. Ezio Levi, Ad. Coester. Crawford, Henriquez Ureña, Arluro Farinelli, Lucien-Paul Thomas, Francisco A. Icaza, Hugo Schuchardt y muchos otros que seria innecesario citar.

Los temas tratados son numerosos. Hay muchos trabajos sobre el teatro clásico español; contribuciones al estudio de los problemas filológicos arábigo-españoles, hispano-galaicos, etc.: nuevas investigaciones sobre el vasco y sobre los dialectos judeo-españoles; capitulos de valia singular sobre la Filosofia del lenguaje, sobre Fonética, etc.; estudios de literatura comparada sobre las influencias españolas en diversas literaturas extranjeras: contribuciones a la critica de los romances, y muchísimos otros temas que sería largo enumerar.

El homenaje fué ofrecido a Menéndez Didal por su discípulo Américo Castro, en un discurso sobrio e intimo. lleno de expresiones cordiales y cariñosas y que no podemos resistir al placer de reproducir, siquiera en parte. Gracias a usted-dice Castro al maestro-comenzó a cultivarse en España una ciencia vacante desde los lejanos tiempos de Nebrija, Valdés Sánchez. Correas y Alderete. Cuando Europa-ha poco más de un siglo -emprendió ardorosamente la investigación de los idiomas y de su sentido dentro de la cultura. España permaneció soñolienta y bostezante, sin aportar a la común tarea ni aun aquellas nociones que más habrian sido de esperar: las concernientes a su propia lengua. Sin la noble aclividad de los hispanoamericanos Bello y Cuervo, el siglo XIX no habría poseido páginas en español dignas de figurar en la historia de la filologia cien. tifica. La Gramática y la Historia de nuestra lengua, de lo que más cerca roza el alma y la sensibilidad nacionales, echaron sus bases merced, sobre todo, al esfuerzo de los extranjeros.

Más adelante el crítico se ocupa de los primeros trabajos de Menéndez Pidal, de su libro sos Infantes de Lara, y de sus fundaciones para intensificar los estudios de historia literaria. Luego dice: Lo que usted ha hecho en treinta años de con- 
tinuo esfuerzo está explicado en la biografia inserta al final de estos tres gruesos volúmenes de homenaje, que hoy tenemos el placer de ofrendarle en nombre de sus discipulos y amigos al cumplirse veinticinco años de su magisterio en la Universidad de Madrid. El nombre de homenaje no me agrada mucho: hace pensar en vistosos pergaminos, en banquetes o condecoraciones, formas externas y vulgarizadas con que suele satisfacerse la humana vanidad. Estos tres volúmenes tienen otro sentido. Son, por lo pronto, obra de austeridad, ya que en ellos no hay una sola palabra de lisonja o elogio; sólo hay trabajo. Desde hace tiempo se ha introducido la costumbre en el mundo de la ciencia de presentar a sus más eximios cultivadores una colección de esfuerzos individuales. Los homenajes de otra indole suponen adhesión más bien exterior y. sobre todo. efimera: en obras de esta clase se tiende a que el rasgo de simpatía sea, a la vez, eficaz y duradero para la misma ciencia. ¿Qué mayor galardón que suscitar un considerable incremento en investigaciones coincidentes, nacidas en torno a un amplio movimiento de simpalia y de respeto entre quienes forman nuestro gremio internacional? $\mathrm{Y}$ por otra parte, ¿qué mayor muestra de estima podemos darle que hacer en su honor lo que sabemos y tenemos por oficio? Cuando el juglar de la leyenda quiso ofrendar a Santa María algo personal y muy valioso, no recitó ante ella las usuales plegarias, sino que practicó ante ella sus habilidades más exquisitas. Ási ahora unos cuantos aficionados al deporte histórico han venido a jugar ante usted una partida un tanto larga y empeñada: tan larga. que ocupa más de 2,200 páginas en cuarto muy mayor».

Luego el señor Castro hace alusión al trabajo de los españoles en la ciencia. que va aumentando con el tiempo y termina por desear al señor Menéndez Pidal. en nombre de todos los colaboradores del Homenaje. smuchos y venturosos años delabors.

A confinuación el señor Navarro Tomás relató diversos detalles relerentes al origen del Homenaje y a su impresión, elogiando a los directores de la casa Hernando por su desinterés y entusiasmo para encarar la publicación. Dijo: 
-Adquirieron letra nueva para estrenarla en esta obra, encargaron su composición a los tipógrafos más expertos, se hicieron fabricar expresamente el papel en que ha sido impresa. acordaron con generosidad regalar un ejemplar de la misma a cada colaborador, hicieron además una corta tirada especial en magnifico papel de hilo y no pusieron ningún inconveniente a que lo que al principio creímos que habia de ser una obra en dos tomos, de unas 600 páginas cada uno, viniese a convertirse, por ampliaciones sucesivas, en estos tres gruesos volúmenes, cuyas 2,263 páginas representan casi el doble de lo que se había calculados.

En seguida hizo uso de la palabra el señor Menéndez Didal, para agradecer el obsequio que se le hacia y para dar a lodos los colaboradores una prueba de su sentimiento al recibirlo: Comenzó el maestro por felicitar a los impresores por el lujo de la publicación. que renueva, dijo, elos buenos tiempos de la lipografía española dieciochisla, demasiado olvidada al presente por urgencias del abaratamiento industrial, que merma y apoca todo lo que concierne al arte del libros: Luego tributó sus agradecimientos a los organizadores del Homenaje y a los colaboradores del mismo. y agregó: _Unos de ustedes fueron hace mucho mis discipulos. los que primero me acompañaron por el apartado camino. y en estos momentos me proporcionan la mayor satisfacción, la del padre que ve a su hijo excederle en valía, la del que aprende del antiguo discipulo. Otros de ustedes son discípulos de los que fueron mis alumnos. Todos comparten las preocupaciones diarias de ahora y de antes, y bien podemos recordar con tranquilidad los penosos años del comienzo, en que era más dura que ahora la lucha por someter a un mélodo austeramente cientifico una porción de cuestiones y problemas que entre nosotros solian andar muy fuera de él. Disfrutábamos entonces en abundancia los beneficios de la hostil reprobación y del leal disentimiento; pero contamos en seguida con el moral apoyo de algún insigne maestro: mis recuerdos imborrables de gratitud van ahora hacia los que ya han 
desaparecido: Gastón Paris, Menéndez Pelayo, Morel-Fatio. Enrique Morf?.

Luego el maestro hizo referencia a los esfuerzos realizados para quebrantar la indiferencia gereral respecto de los estudios de su especialidad. Ella, dijo, se ha trocado ahora en una benévola simpalía y en una colaboración cada dia más numerosa que hace fecundos todos los esfuerzos. Agregó que este Homenaje. en que se hallaba viva la presencia de ciento treinta amigos esparcidos en lodas las latitudes, sería siempre cuna satisfacción capital en su vidas. Al finalizar, dijo: Al llegar a la edad de la vida cuando el tiempo fluye con la mayor rapidez, que anuncia la proximidad del abismo en que irá a perderse para siempre. se ve demasiado claro que lo que uno ha hecho en la vida es lo minimo de lo que puede y debiera hacer. Enfonces se agradece doblemente el afectuoso aliento que uno recibe con la simpatia de los demás para continuar lo poco que le queda del camino. Gracias. pues, de todo corazón a todos los que han cooperado a la publicación que recibo en este instantes.

En suma, el homenaje a Menéndez Pidal ha sido una eficaz y sincera manifeslación del aprecio que por el maestro hispano sienten los más destacados representantes de la ciencia filólogica y literaria del mundo. Como demostración permanente de él quedarán esos tres abultados volúmenes en que se han condensado los trabajos de tantos sabios investigadores y criticos de todos los pueblos cultos.

R. S. C. 